\title{
UCSF settles lawsuit over research costs
}

[SAN DIEGO] In an unprecedented decision, a private US foundation will formally agree this week to pay $\$ 25$ million to settle a lawsuit over allegations concerning a longrunning scheme under which the University of California at San Francisco (UCSF) claims to have been cheated out of income from research funds.

The foundation's founder and chief executive is Dennis T. Mangano, a physician who until last year was a vice-chairman of anaesthesia at UCSF. He is facing charges from the university of violating a large number of academic policies, including intentionally misappropriating the research and intellectual property of colleagues.

The main legal charge against Mangano, in a suit filed by another UCSF faculty member, is that he used his Ischemia Research (IREF) and Education Foundation to secure at least $\$ 50$ million in grants from drug companies in California and Europe without paying the university the full costs of using its facilities. Court records state that UCSF received only $\$ 2$ million from the grants.

Non-profit foundations controlled by university professors have caused increasing concern at the University of California's five medical campuses, which have been hit hard by budgetary restraints. The foundations developed into multi-million-dollar enterprises as pharmaceutical companies increased their funding of clinical trials through the organizations, which were often able to make free use of university facilities.

Mangano, who insists that he did nothing wrong, says that university officials were aware of his foundation's activities, which were designed to capitalize on the combined efforts of associated researchers at 160 institutions in the United States and elsewhere.

Arguing that the board of the foundation has agreed to settle the lawsuit without his involvement, Mangano says: "The public should look at the bottom line - which is that money [intended] to be used for finding a cure for heart attack and stroke is now being diverted. I believe this sets a very bad precedent for non-profit foundations."

Although the lawsuit is due to be officially settled tomorrow (31 January) after more than two years of litigation, the UCSF allegations against Mangano for his academic behaviour remain unresolved - a fact that has troubled some of those familiar with the alleged offences.

The concern arises from the fact that, although the allegations of academic misconduct were made nearly three years ago, UCSF officials have yet to complete their internal investigation, or to take action over the allegations of Mangano's abuse of professors and students, and of the collegial process by which research information is

shared. Such inaction has raised questions about how the university deals with allegations against revenue-producing clinical researchers at its hospitals facing financial difficulties.

The importance of such questions is growing as UCSF and Stanford University merge their hospital facilities into a single, private organization, whose operations will be largely shielded from public scrutiny. One widespread fear is that the publicly owned UCSF facility and its employees could be abused more easily after the merger.

UCSF officials decline to comment on either the Mangano lawsuit or the academic inquiry. It was Charles A. Richardson, an assistant adjunct professor at the university, who filed the lawsuit in a state court under a seldom-used California statute that allows a 'whistleblower' to sue to recover funds for a stated institution - in this case UCSF.

Under the law, most of the recovered funds go to the state institution, but the whistleblower and his or her attorney also can share the award. The California law is similar to the federal whistleblower law, which has been used to recover money for the National Institutes of Health after false claims in grant applications. But legal authorities say this is the first time the California law has been used in such a case, whose \$25-million settlement is unprecedented in American academic history.

Under the terms of the settlement filed in San Francisco Superior Court, UCSF will receive $\$ 19.2$ million from the foundation, Richardson will - in line with federal legislation allocating a percentage of money recovered as a reward to whistleblowers get $\$ 1.5$ million, and his attorney's fees and costs of $\$ 4.3$ million will be paid.

\section{UK's top research groups win extra funds}

[LONDON] The Higher Education Funding Council for England, which distributes government funding to universities, announced last week that it is introducing a new method for allocating research money which will ensure that the highest-rated universities will receive a greater proportion of total funds.

The money received by universities is based directly on the scores of individual departments in the recent Research Assessment Exercise (RAE) (see Nature 385, $3 ; 1997)$. In addition to increasing the funding gap between departments reaching different levels of assessment, new cost ratings to be used to weight the initial distribution of funds between subjects will bring relatively more money to life sciences and physics and less to pure mathematics.

Mangano, who remains a UCSF professor and whose anaesthesia practice is based at the Veterans Administration Medical Center in San Francisco, remains opposed to the settlement. "These dollars were to perform research on high-risk surgical patients," he says. "I find it very discouraging that powerful individuals have found a way to [turn] the money [to a] personal gain."

Richardson declines to comment on the settlement (as do three other UCSF researchers with whom Richardson filed the academic complaint against Mangano in June 1994). But sources at the university say he hopes the university will use the $\$ 19.2$ million to help restore the fortunes of those whose careers have been adversely affected by the actions of Mangano and his foundation.

In the academic complaint, the four researchers alleged that Mangano significantly interfered with "free inquiry and exchange of ideas", that he "prevented the extension of knowledge by faculty, fellow and students", used his "position of power" to "cause harm to a student for professional and personal reasons" and "harassed and intimidated" UCSF researchers so they could not carry out their university jobs.

The four researchers requested an audit of Mangano's activities, but the audit largely completed several months ago - has not yet been released by UCSF authorities, who say it may be available in a month.

Commenting on how Mangano and his foundation operated, one former UCSF official says privately: "There has never been anything like this in the history of higher education. This was full-blown [use of] the university's name and pulling in millions of dollars" with little regard to the impact on the university.

Rex Dalton

The funding council will share out about $\mathfrak{E 6 3 0}$ million (US\$1.02 billion) next month between 136 institutions, on the basis of the total quality of research in each university's departments. RAE grades have been converted into a 'funding factor', which starts at 1 for grade $3 b$ and increases by 50 per cent each step to grade 5 , with a 20 per cent premium for grade $5^{\star}$ - for a factor of 4.05 .

Even with this special treatment, $5^{*}$ departments will receive little more than did all departments awarded 5 in academic year 1996-97 as a result of an increase in overall research performance by British universities. Departments that received a score of 1 or 2 will receive no government funds for research, although they are free to raise funds elsewhere, or to transfer them from their teaching budgets. 